\title{
Evaluation Index System of Enterprise WeChat Official Account Operational Capability
}

\author{
Xia Liyu $^{1, \mathrm{a}}$,Wang Youzi ${ }^{2, \mathrm{~b}}$,Wang $\operatorname{Han}^{3, \mathrm{c}}$ \\ ${ }^{1}$ State Grid Energy Research Institute Management Consulting Institute Beijing, China \\ ${ }^{2}$ State Grid Energy Research Institute Management Consulting Institute Beijing, China \\ ${ }^{3}$ State Grid Energy Research Institute Management Consulting Institute Beijing, China
}

\begin{abstract}
In order to provide reference standard for evaluating the operational capability of WeChat official account, we build a evaluation index system to improve the management level of publicity work. First, the evaluation index system of WeChat official account is designed. Then, the method of determining the weight of subjective and objective indicators combining Delphi method and principal component analysis is proposed. The per capita method for eliminating the influence of the scale of enterprises and the logarithmic normalization method for handling uneven data are proposed. Finally, the empirical study of the 12 official accounts of State Grid is made. The evaluation index system of WeChat official account includes 4 first level indicators and 15 two level indicators. This study proposes that the index system and data processing method are scientific.
\end{abstract}

\section{Introduction}

Since it was put into the market, wechat has become the main way for the public to communicate and obtain information through continuous development and optimization. According to the wechat data report in 2018, the daily living volume of wechat has exceeded 1 billion people. As an additional function of WeChat, WeChat official account number has been launched since August 2012. With its advantages of information push, automatic response and one to one communication, WeChat official account has quickly become an important information carrier and communication platform in the new media era. According to the WeChat data report 2017, the number of WeChat official account has exceeded 10 million in September 2017, including 3 million 500 thousand monthly active accounts. The rapid function iteration, massive content creation, and the surge of fans' attention have promoted the steady development of wechat public platform, making it transform from one-dimensional content output function to multi-dimensional marketing promotion, online service, public opinion processing and other functions.

The steady development of platform and the multidimensional transformation of functions attract various enterprises to launch WeChat official account, and play different roles in issuing official account information and directly interacting with customers according to their functional positioning. Taking the State Grid as an example, the primary and secondary accounts are mainly to release the company's news, introduce the company's services, and publicize the company's image, while the third and fourth level accounts generally focus on disseminating internal information and providing professional services. Compared with other official account numbers, WeChat official account shows remarkable characteristics of fast dissemination, wide coverage and strong interaction. Under current new media environment, WeChat official account has become an important topic in the management of enterprise publicity. Managers are concerned not only with current dissemination effect of the information released, but also on long-term operation capability of WeChat official account. Therefore, evaluation index system is needed to provide reference standard for evaluating WeChat official account operational capability and improve the management level of publicity work.

WeChat official account has aroused great enthusiasm in academic circles. The research method is mainly qualitative analysis, and the related results are mainly focused on the propagation characteristics of WeChat official account, the communication mechanism, the communication power, and the communication effect. The evaluation of WeChat official account operational capability is post evaluation and belongs to the category of communication effect. Scholars carry out innovative research according to the characteristics of evaluation objects. Li Mingde has built up the media WeChat official account evaluation system based on the platform design, content presentation, message recovery, push frequency and dissemination degree. Ji Fang selected 10 indicators to construct the influence evaluation system of wechat public platform, taking into account the matching degree between the functional content of wechat public platform and user demand, the influence of

axialiyu@sgeri.sgcc.com.cn b ${ }^{b}$ wangyouzi@sgeri.sgcc.com.cn ${ }^{c}$ wanghan@sgeri.sgcc.com.cn 
communication effect and timeliness, and carried out empirical analysis on wechat public platform of five academic journals by TOPSIS method. Yan Yueming drew lessons from the $\mathrm{H}$ index and $\mathrm{R}$ index, and put forward a comprehensive evaluation model of WeChat official account influence by considering the reading quota, the point of praise quantity and the number of articles. Zhan Baoqiang and Nie Chang consider the tangible, useful, responsive, interactive, caring and information quality factors to build WeChat public official account satisfaction index.

Most of the studies focus on the propagation of public numbers when setting up the index system. When evaluating the operation capacity of the subsidiary accounts of large enterprises, such index system seldom considers the diligence and growth of the subsidiary in the process of managing the official account, and can not reasonably evaluate the operation capability, and is not conducive to the promotion of the secondary official account. Therefore, this study considers the four dimensions of communication power, attention, diligence and growth to design the evaluation index system of WeChat official account. Combining Delphi method and principal component analysis, we determine the weight of indicators, innovate logarithmic data normalization method, and select 12 two level official account of State Grid to conduct empirical research.

\section{Design of evaluation index system}

\subsection{Construction Principles}

The following principles should be adhered to in establishing the evaluation index system of WeChat official account.

- Comprehensiveness.In the design of index system, we should take into account the differences of the nature of the company, its location and the development stage. We should take into account the quality, quantity and speed of the operation of the official account.

- Orientation.In the evaluation index system, problems diagnosis and improvement should be highlighted, focusing on guiding enterprises to find their own shortcomings and seeking improvement direction, encouraging enterprises to take the initiative in benchmarking outstanding enterprises, clarifying the direction of efforts and learning from advanced experience.

- Systematicness.The indicators of evaluation system should have a clear logical relationship, which can reflect the influence of official account from different aspects, and also reflect the status and characteristics of official account operation.

- Reliability.In terms of index selection, the indicators that can obtain objective data are given priority to, and the official and background statistical data of the platform are fully utilized, and the statistical caliber and mode of data are defined clearly.

\subsection{Index Selection}

In order to build an evaluation index System that can comprehensively reflect the operational capability of WeChat official account, the following indicators are identified by literature research and expert discussion. The index composition and index descriptions are shown in Table 1. The official account can be used to evaluate the operation of WeChat public number from different angles. The communication reflects the effect of information dissemination through the interaction of all articles and headlines. The attention reflects the public number's attention through the fans' situation. The diligence reflects the effort the enterprise's official account through the quantity of articles published. The growth reflects the growth of WeChat official account.

Table1. enterprise WeChat official account operational

\begin{tabular}{|c|c|c|}
\hline Primary indicators & Secondary indicators & Index description \\
\hline \multirow{6}{*}{ Communication A } & Overall reading $\mathrm{A} 1$ & $\begin{array}{l}\text { Average daily readings of all } \\
\text { articles }\end{array}$ \\
\hline & Overall like A2 & Average daily likes of all articles \\
\hline & Overall forwarding A3 & $\begin{array}{l}\text { Average daily forwarding of all } \\
\text { articles }\end{array}$ \\
\hline & Headline reading A4 & $\begin{array}{l}\text { Average daily readings of } \\
\text { headlines }\end{array}$ \\
\hline & Headline like A5 & Average daily likes of headlines \\
\hline & Headline forwarding A6 & $\begin{array}{l}\text { Average daily forwarding of } \\
\text { headlines }\end{array}$ \\
\hline \multirow{3}{*}{ Attention B } & Number of fans B1 & Average number of fans per day \\
\hline & Fans Sticky B2 & $\begin{array}{l}\text { Average daily number of fans } \\
\text { cancelled }\end{array}$ \\
\hline & Fans growth B3 & $\begin{array}{l}\text { Difference between the number of } \\
\text { fans of two periods }\end{array}$ \\
\hline \multirow{2}{*}{ Diligence C } & Number of articles $\mathrm{C} 1$ & Total number of articles \\
\hline & Article time distribution $\mathrm{C} 2$ & $\begin{array}{l}\text { variation of daily average number } \\
\text { of articles published }\end{array}$ \\
\hline \multirow{4}{*}{ Growth D } & Reading growth rate D1 & $\begin{array}{l}\text { Growth rate of average daily } \\
\text { readings }\end{array}$ \\
\hline & Like growth rate D2 & Growth rate of average daily likes \\
\hline & Forwarding growth rate D3 & $\begin{array}{l}\text { Growth rate of average daily } \\
\text { forwarding }\end{array}$ \\
\hline & Fans growth rate $\mathrm{D} 4$ & Growth rate of average daily fans \\
\hline
\end{tabular}

\section{Data processing method}

\subsection{Weight Calculation Method}

Delphi method is more convenient in operation, which can be used as a subjective method to determine the weight of indicators. Principal component analysis method based on the correlation coefficient matrix between indicators, considering the correlation between indicators, can be used as an objective method to determine the weight of indicators. In order to take into account the advantages of expert wisdom and data characteristics, this study uses a combination of subjective and objective methods to determine the index weight, that is, the combination of Delphi method and principal component analysis method. 


\subsubsection{Delphi Method}

Relevant experts in the field of new media are selected to score the importance of indicators according to the actual situation and work experience of enterprises, and the importance of experts is weighted according to the level and specialty of experts. The subjective weight score is the weighted average of experts' scores.

$\mathrm{m}$ experts are invited to score the weights of $n$ evaluation indexes. The scoring result of each expert is $\left[X_{1}, \ldots, X_{\mathrm{n}}\right]$, and the role weight of $\mathrm{m}$ experts is $\left[\alpha_{1}, \ldots, \alpha_{\mathrm{m}}\right]$. Experts give a score of 1-10 according to their judgment on the importance of indicators, 1 represents the least important and 10 represents the most important. Assuming that the $\mathrm{j}$-th expert's scoring result on the $\mathrm{i}$-th evaluation index is $X_{\mathrm{ij}}$, then the weight result of the $\mathrm{i}$-th evaluation index is:

$$
\omega_{\mathrm{i}}=\frac{\sum_{\mathrm{j}=1}^{\mathrm{m}} \alpha_{\mathrm{j}} X_{\mathrm{ij}}}{\sum_{\mathrm{i}=1}^{n} \sum_{\mathrm{j}=1}^{\mathrm{m}} \alpha_{\mathrm{j}} X_{\mathrm{ij}}}
$$

\subsubsection{Principal Component Analysis}

Principal component analysis (PCA) reduces the dimensions of multiple evaluation indexes by linear transformation, and ensures that the reduced indexes retain the information provided by the original indicators as much as possible. The size of the information is usually measured by the sum of squares of deviation or variance. Principal component analysis mainly determines the weight of indicators based on the fluctuation of data, and calculates the weights by variance contribution rate and coefficient of indicators in the linear combination of principal components.

Firstly, the correlation coefficient matrix and the maximum variance method are used for principal component analysis, and the total variance and component matrix are obtained. It is suggested that the principal components with characteristic roots greater than 1 should be retained. Then, the coefficient $\beta$ of each principal component are divided by the square root of the corresponding characteristic root $\gamma$, and the initial weight value $\mathrm{w}$ of the corresponding index is calculated according to the variance contribution degree. Assuming that $\mathrm{P}$ principal components are selected, the coefficient corresponding to the $\mathrm{i}$-th index of the $\mathrm{k}$-th principal component becomes:

$$
\beta_{k i}^{*}=\frac{\beta_{\mathrm{ki}}}{\sqrt{\lambda_{\mathrm{k}}}}
$$

Then the weight of the i-th index is as follows:

$$
\mathrm{w}_{\mathrm{i}}=\frac{\sum_{\mathrm{k}=1}^{p} \beta_{k i}^{*} \times \gamma_{k}}{\sum_{\mathrm{k}=1}^{p} \gamma_{k}}
$$

Finally, the initial weight value is normalized to get the final weight value:

$$
W_{\mathrm{i}}=\frac{\mathrm{w}_{\mathrm{i}}}{\sum_{\mathrm{i}=1}^{\mathrm{n}} \mathrm{w}_{\mathrm{i}}}
$$

\subsubsection{Weighting of Subjective and Objective Methods}

According to the principle component analysis method and Delphi method, the subjective weight $\omega_{\mathrm{i}}$ and objective weight $W_{\mathrm{i}}$ of the $\mathrm{i}$ evaluation index are calculated respectively, and the weights of the objective and subjective results are set according to the evaluation needs, and the weighted average of the index weight results is used to obtain the final weight.

The weight of subjective evaluation results is set as $\theta$, and that of objective evaluation results is $1-\theta$. If the weighted result of the $i$-th evaluation index is $\theta \omega_{\mathrm{i}}+(1-\theta) W_{\mathrm{i}}$, the final weight result of the i-th evaluation index is:

$$
\bar{\omega}_{\mathrm{i}}=\frac{\theta \omega_{\mathrm{i}}+(1-\theta) W_{\mathrm{i}}}{\sum_{\mathrm{i}=1}^{\mathrm{n}}\left[\theta \omega_{\mathrm{i}}+(1-\theta) W_{\mathrm{i}}\right]}
$$

Because only the data of secondary indicators can be directly obtained, this study directly uses the method of subjective and objective combination to determine the weight of secondary indicators, and Delphi method is used to determine the weight of primary indicators.

\subsection{Per Capita Method}

In order to reduce the influence of the volume and location of enterprises on the WeChat official account's communication and attention, we can use the population quantity to process the index per capita.

Combined with the actual situation of the enterprise, the average number of customers or employees in the evaluation period can be considered as the representative of the population. Compared with the number of employees, the number of customers can reflect the scope of WeChat's official account and the size of its audience. Therefore, the number of customers is chosen as the representative of the population quantity in the process of per capita treatment, and the total number of customers is divided by the number of customers, so as to eliminate the effect of scale difference.

In addition, because the number of customers of some enterprises is too small or too large, it is easy to greatly exaggerate or reduce the value of indicators after per capita, which will affect the objectivity of evaluation indicators. This study suggests that the $1 / 4$ quantile and $3 / 4$ quantile of the total number of customers should be used to adjust the number of customers of each enterprise. If the actual number of customers of an enterprise is less than $1 / 4$ quantile, the number of per capita customers of the enterprise is $1 / 4$ quantile; if the actual number of customers of an enterprise is between $1 / 4$ quantile and 3/4 quantile, the value of per capita customer number of the enterprise does not need to be adjusted; if the actual number of customers of an enterprise is greater than $3 / 4$ 
quantile, the number of per capita customers of the enterprise is taken as $3 / 4$ quantile.

\subsection{Data Normalization}

By normalizing the data, the influence of order of magnitude and dimension can be eliminated, and the relative number in a certain range can be obtained, so that the data can be summed up or compared directly.

\subsubsection{Data is Evenly Distributed}

In the conventional normalization method, if the data distribution is relatively uniform, the maximum value and minimum value can be directly used to normalize the index value to the interval of $[0,100]$ :

$$
Z_{i}=\frac{X_{\mathrm{i}}-X_{\min }}{X_{\max }-X_{\min }} \times 100
$$

If there is an abnormal value in the data, the maximum value and minimum value after excluding the abnormal value are used to normalize. The corresponding larger abnormal value is 100 , and the smaller abnormal value is 0 :

$$
Z_{i}= \begin{cases}0 & , X_{\mathrm{i}}<X_{\min }^{*} \\ \frac{X_{\mathrm{i}}-X_{\min }^{*}}{X_{\max }^{*}-X_{\min }^{*}} \times 100 & , X_{\min }^{*}<X_{\mathrm{i}}<X_{\max }^{*} \\ 100 & , X_{\mathrm{i}}>X_{\max }^{*}\end{cases}
$$

\subsubsection{Data is Unevenly Distributed}

In practice, the data distribution of most indicators is not uniform, which shows the characteristics of "there are some maximum outliers, but there are significant differences between the maximum outliers". If the conventional normalization method is used, the difference between the data will be reduced, and the evaluation results can not objectively reflect the real situation of the data. Therefore, according to the characteristics of wechat data, this study proposes the following logarithmic data normalization method, which can not only reflect the difference between data, but also reduce the uneven of data distribution.

$$
Z_{i}=\log _{\alpha}\left[1+\frac{X_{\mathrm{i}}-X_{\min }}{X_{\max }-X_{\min }} \times(\alpha-1)\right] \times 100
$$

If there are outliers in the data, the maximum value $X_{\max }^{*}$ and minimum value $X_{\text {min }}^{*}$ after excluding outliers are used for normalization:

$$
Z_{i}= \begin{cases}0 & , X_{\mathrm{i}}<X_{\min }^{*} \\ \log _{\alpha}\left[1+\frac{X_{\mathrm{i}}-X_{\min }^{*}}{X_{\max }^{*}-X_{\min }^{*}} \times(\alpha-1)\right] \times 100 & , X_{\min }^{*}<X_{\mathrm{i}}<X_{\max }^{*} \\ 100 & , X_{\mathrm{i}}>X_{\max }^{*}\end{cases}
$$

In the selection of logarithm base $\alpha$, the square of index median is suggested in this study, so that the normalized value of median is 50 . The stability of the median is used to reduce the influence of abnormal value on the normalized value.

\section{Empirical analysis}

\subsection{Data Description}

This study selected 12 WeChat official account as the research object and obtained the original data from the official background in the April 2019.

Through the analysis of the original data, it can be found that each index is greatly affected by the size of the enterprise, and the data distribution is uneven. Therefore, it is necessary to use the per capita and logarithmic normalization methods proposed in this study. Before the weight calculation and normalization, the per capita treatment is carried out for the secondary indicators set under the first level indicators' communication power and attention, so as to eliminate the influence of enterprise volume.

\subsection{Index Weight Calculation}

Due to the space limitation, it only shows the weight calculation process of six secondary indicators set under the first level index communication power. The first step is to use the Delphi method to calculate the subjective weight. The subjective weight of the index is obtained by combining scores of several experts and weighted average, as shown in Table 2.

Table2. subjective weight of secondary index of

\begin{tabular}{|c|c|c|c|c|}
\hline \multirow{2}{*}{$\begin{array}{c}\text { Primary } \\
\text { indicators }\end{array}$} & $\begin{array}{c}\text { Secondary } \\
\text { indicators }\end{array}$ & $\begin{array}{c}\text { subjecti } \\
\text { ve } \\
\text { weight }\end{array}$ & $\begin{array}{c}\text { objectiv } \\
\text { e weight }\end{array}$ & $\begin{array}{c}\text { final } \\
\text { weight }\end{array}$ \\
\hline \multirow{4}{*}{ Communicatio } & $\begin{array}{c}\text { Overall } \\
\text { reading A1 }\end{array}$ & 0.48 & 0.16 & 0.35 \\
\cline { 2 - 5 } & $\begin{array}{c}\text { Overall like } \\
\text { A2 }\end{array}$ & 0.16 & 0.10 & 0.14 \\
\cline { 2 - 5 } & $\begin{array}{c}\text { Overall } \\
\text { forwarding } \\
\text { A3 }\end{array}$ & 0.16 & 0.11 & 0.14 \\
\cline { 2 - 5 } & $\begin{array}{c}\text { Headline } \\
\text { reading A4 }\end{array}$ & 0.12 & 0.19 & 0.15 \\
\cline { 2 - 5 } & $\begin{array}{c}\text { Headline like } \\
\text { A5 }\end{array}$ & 0.04 & 0.19 & 0.10 \\
\cline { 2 - 5 } & $\begin{array}{c}\text { Headline } \\
\text { forwarding } \\
\text { A6 }\end{array}$ & 0.04 & 0.25 & 0.12 \\
\hline
\end{tabular}

In the second step, the objective weight is calculated by principal component analysis. Firstly, the principal component analysis was performed on the per capita data, and the total variance was obtained as shown in Table 3.

Table3. Total variance of interpretation

\begin{tabular}{|c|c|c|c|}
\hline Component & Total & $\begin{array}{c}\text { \% of } \\
\text { variance }\end{array}$ & $\begin{array}{c}\text { Cumulative } \\
\text { \% }\end{array}$ \\
\hline 1 & 3.229 & 53.814 & 53.814 \\
\hline 2 & 1.729 & 28.813 & 82.627 \\
\hline 3 & 0.826 & 13.768 & 96.395 \\
\hline
\end{tabular}




\begin{tabular}{|c|c|c|c|}
\hline 4 & 0.191 & 3.190 & 99.586 \\
\hline 5 & 0.020 & 0.328 & 99.914 \\
\hline 6 & 0.005 & 0.086 & 100.000 \\
\hline
\end{tabular}

The first three principal components obtained by principal component analysis accounted for $96.395 \%$ of variance variance. The rotated component matrix can also be obtained based on principal component analysis, as shown in Table 4. According to the basic steps of determining the index weight coefficient by principal component analysis, the objective weight of each index is obtained, as shown in Table 2.

Table4. Component matrix after rotation

\begin{tabular}{|c|c|c|c|}
\hline & Component 1 & Component 2 & Component 3 \\
\hline $\begin{array}{c}\text { Overall } \\
\text { reading A1 }\end{array}$ & 0.079 & 0.432 & 0.874 \\
\hline $\begin{array}{c}\text { Overall like } \\
\text { A2 }\end{array}$ & 0.552 & -0.144 & 0.771 \\
\hline $\begin{array}{c}\text { Overall } \\
\text { forwarding } \\
\text { A3 }\end{array}$ & -0.122 & 0.971 & 0.115 \\
\hline $\begin{array}{c}\text { Headline } \\
\text { reading A4 }\end{array}$ & 0.899 & 0.199 & 0.320 \\
\hline $\begin{array}{c}\text { Headline like } \\
\text { A5 }\end{array}$ & 0.991 & 0.024 & 0.095 \\
\hline $\begin{array}{c}\text { Headline } \\
\text { forwarding } \\
\text { A6 }\end{array}$ & 0.392 & 0.906 & 0.138 \\
\hline
\end{tabular}

In the third step, set the adjustment parameter of subjective and objective weights $\theta=0.6$, and weight the results of subjective and objective methods to obtain the final secondary index weight, as shown in Table 2 .

Using the above method, the subjective weight and objective weight of each secondary index can be calculated, and the subjective weight of each primary index can be calculated by using Delphi method. The calculation results are shown in Table 5.

Table5. Calculation results of subjective and objective weights of all levels of indicators

\begin{tabular}{|c|c|c|c|c|c|}
\hline $\begin{array}{c}\text { Primary } \\
\text { indicato } \\
\text { rs }\end{array}$ & $\begin{array}{c}\text { Objecti } \\
\text { ve } \\
\text { weight }\end{array}$ & $\begin{array}{l}\text { Secondary } \\
\text { indicators }\end{array}$ & $\begin{array}{c}\text { Subjecti } \\
\text { ve } \\
\text { weight }\end{array}$ & $\begin{array}{l}\text { Objectiv } \\
\text { e weight }\end{array}$ & $\begin{array}{c}\text { Final } \\
\text { weight }\end{array}$ \\
\hline \multirow{6}{*}{$\begin{array}{l}\text { Commun } \\
\text { ication A }\end{array}$} & \multirow{6}{*}{0.43} & $\begin{array}{c}\text { Overall reading } \\
\mathrm{A} 1 \\
\end{array}$ & 0.48 & 0.16 & 0.35 \\
\hline & & Overall like A2 & 0.16 & 0.10 & 0.14 \\
\hline & & $\begin{array}{c}\text { Overall } \\
\text { forwarding A3 } \\
\end{array}$ & 0.16 & 0.11 & 0.14 \\
\hline & & $\begin{array}{c}\text { Headline } \\
\text { reading A4 }\end{array}$ & 0.12 & 0.19 & 0.15 \\
\hline & & Headline like A5 & 0.04 & 0.19 & 0.10 \\
\hline & & $\begin{array}{c}\text { Headline } \\
\text { forwarding A6 }\end{array}$ & 0.04 & 0.25 & 0.12 \\
\hline \multirow{3}{*}{$\begin{array}{l}\text { Attention } \\
\text { B }\end{array}$} & \multirow{3}{*}{0.26} & $\begin{array}{c}\text { Number of fans } \\
\text { B1 }\end{array}$ & 0.55 & 0.25 & 0.43 \\
\hline & & $\begin{array}{c}\text { Fans Sticky } \\
\text { B2 }\end{array}$ & 0.23 & 0.41 & 0.30 \\
\hline & & Fans growth B3 & 0.22 & 0.34 & 0.27 \\
\hline \multirow{2}{*}{$\begin{array}{l}\text { Diligenc } \\
\text { e C }\end{array}$} & \multirow{2}{*}{0.13} & $\begin{array}{l}\text { Number of } \\
\text { articles } \mathrm{C} 1\end{array}$ & 0.73 & 0.45 & 0.62 \\
\hline & & $\begin{array}{c}\text { Article time } \\
\text { distribution } \mathrm{C} 2\end{array}$ & 0.27 & 0.55 & 0.38 \\
\hline \multirow{4}{*}{$\begin{array}{l}\text { Growth } \\
\text { D }\end{array}$} & \multirow{4}{*}{0.18} & $\begin{array}{l}\text { Reading growth } \\
\text { rate D1 }\end{array}$ & 0.49 & 0.39 & 0.45 \\
\hline & & $\begin{array}{l}\text { Like growth rate } \\
\text { D2 } \\
\end{array}$ & 0.21 & 0.18 & 0.20 \\
\hline & & $\begin{array}{c}\text { Forwarding } \\
\text { growth rate D3 } \\
\end{array}$ & 0.12 & 0.19 & 0.15 \\
\hline & & $\begin{array}{c}\text { Fans growth rate } \\
\text { D4 } \\
\end{array}$ & 0.18 & 0.24 & 0.20 \\
\hline
\end{tabular}

\subsection{Index Normalization}

Combined with data characteristics, the data type is normalized by using the (8) and (9). Combined with the final weight, the communication strength and ranking of WeChat official account can be calculated. The score and ranking of other first level indicators can also be calculated according to this method.

Table6. Index normalization and score results of

\begin{tabular}{|c|c|c|c|c|c|c|c|}
\hline $\begin{array}{l}\text { Enterp } \\
\text { rise }\end{array}$ & A1 & $\mathbf{A 2}$ & A3 & A4 & A5 & A6 & $\mathbf{A}$ \\
\hline 1 & 100.00 & 82.91 & 100.00 & 81.51 & 80.10 & 100.00 & 92.84 \\
\hline 2 & 83.57 & 100.00 & 79.65 & 100.00 & 100.00 & 100.00 & 91.40 \\
\hline 3 & 100.00 & 86.70 & 72.24 & 68.49 & 88.28 & 57.46 & 83.25 \\
\hline 4 & 85.29 & 74.57 & 79.05 & 80.69 & 100.00 & 79.08 & 82.95 \\
\hline 5 & 93.21 & 100.00 & 59.45 & 78.12 & 100.00 & 38.01 & 81.23 \\
\hline 6 & 73.91 & 56.95 & 74.81 & 55.31 & 61.42 & 74.17 & 67.65 \\
\hline 7 & 75.08 & 46.70 & 69.56 & 74.52 & 66.06 & 60.67 & 67.62 \\
\hline 8 & 58.85 & 43.49 & 100.00 & 41.95 & 39.84 & 90.64 & 61.84 \\
\hline 9 & 29.15 & 38.57 & 36.46 & 62.36 & 93.88 & 41.81 & 44.47 \\
\hline 10 & 0.00 & 0.00 & 80.99 & 47.05 & 66.66 & 69.30 & 33.38 \\
\hline 11 & 9.85 & 5.33 & 62.27 & 40.28 & 40.54 & 58.76 & 30.06 \\
\hline 12 & 39.33 & 29.07 & 0.00 & 0.00 & 0.00 & 0.00 & 17.84 \\
\hline
\end{tabular}

Table 6 shows that the logarithmic normalization method proposed in this study can eliminate the influence of uneven data distribution to a certain extent. The method transforms the data into a score between 0 and 100, and assigns the larger outliers to 100 . Combined with the weight of the two indicators, we can see that the stronger the overall communication power of WeChat official account is, the greater the official account's transmission power will be. WeChat official account of the same enterprise has strong consistency in reading, like and forwarding amount, that is, when a certain index score is higher, the remaining index scores are relatively high.

\section{5 conclusion}

This study uses the method of literature research and expert discussion to design the evaluation index system of WeChat official account operational capability, which includes 4 first level indicators and 15 two level indicators. The weights of indicators are determined by the combination of subjective and objective methods, and the Delphi method and principal component analysis method are combined to give consideration to the advantages of expert wisdom and data characteristics. Combined with the actual situation of the enterprise, the per capita method of eliminating the impact of enterprise volume by the number of customers is proposed, and the logarithmic normalization method is proposed to deal with the uneven distribution data. The empirical study of 12 official accounts of State Grid shows that the index system and 
data processing method proposed in this study are scientific.

The WeChat enterprise official account evaluation index system is applicable to horizontal comparison between different enterprises, and also applies to vertical comparison of different historical periods of the same enterprise. It helps to find out the advantages and disadvantages of WeChat official account from multiple dimensions and find the direction to improve the ability of operation.

\section{References}

1. Huang Wei, Huang Jianqiao, Hu Yue, Li Yuefeng. Evaluation index system of WeChat official account No. [J]. modern intelligence, 2018,38 (03): 99104149 .

2. Cai Qi, Bian Han Yue. See WeChat official account to transmit [J]. news, 2019 (01): 71-78.

3. Wu Zhongtang, Liu Jianhui, Tang Zhenhua. WeChat official account information dissemination factors research [J]. intelligence magazine, 2015,34 (04): 122-126.

4. Xiong Yin, Jiang Shan, Xing Ruonan. Communication characteristics, mechanism and guiding ideas of wechat public opinion [J]. Information science, 2018,36 (11): 54-60

5. Ma Quan en, Zhang Juan. Research on the propagation mechanism of WeChat official account based on SIR model on complex networks [J]. intelligence science, 2018,36 (07): 30-35.

6. Bao Minglin. System dynamics simulation analysis of wechat user behavior [J]. Information science, 2018,36 (03): 81-86116

7. Yan Yi Wen, Zhang Haitao, Sun Siyang, song Tuo. Evaluation of information dissemination effect of government WeChat official account based on BP neural network $[\mathrm{J}]$. library and information work, 2017,61 (20): 53-62.

8. Li Mingde, Gao Ru. Media WeChat public number communication research evaluation based on the 20 WeChat official account of Shaanxi official account, [J]. intelligence magazine, 2015,34 (07): 141-147.

9. Ji Fang, Zhang Xiaheng. Research on the influence of wechat public platform of academic journals -- An Empirical Analysis Based on five CSSCI source journals [J]. Journal of information, 2016,35 (04): 147-151

10. Yan Yueming, Zhao Peng. No way. An evaluation method of the influence of WeChat official account [J]. intelligence magazine, 2016,35 (09): 141-145.

11. Zhan Baoqiang, Wen Wenhao, $\mathrm{Xu}$ Sheng Jun. Empirical Study on principal component optimization of media WeChat official account influence. [J]. intelligence exploration, 2016 (12): 62-68.

12. Nie Changteng, Xie Guihua. Research on operation optimization of WeChat official account based on IPA analysis [J]. Journal of Fujian business school, 2018 (03): 74-81.

13. Zhang Haitao, Zhang Hui ran, Wei Ping, Yin Hui Zi. WeChat official account influence evaluation model research [J]. library and information work, 2019,63 (04): 23-31.I. S. Jacobs and C. P. Bean, "Fine particles, thin films and exchange anisotropy," in Magnetism, vol. III, G. T. Rado and H. Suhl, Eds. New York: Academic, 1963, pp. 271-350. 